\title{
EL AGRICULTOR DIVINO \\ Y OTROS AGRICULTORES \\ EN LOS AUTOS CALDERONIANOS ${ }^{1}$
}

Mariela Insúa

Departamento de Literatura Hispánica

Facultad de Filosofia y Letras

Edificio de Bibliotecas

GRISO-Universidad de Navarra

31080 Pamplona. Navarra. España

minsua@unav.es

[Anuario calderoniano (ISSN: 1888-8046), 4, 2011, pp. 201-216]

En el corpus de los autos calderonianos encontramos un grupo definido de piezas cuya estructura alegórica ${ }^{2}$ se fundamenta en los trabajos del campo, especialmente la labranza, la siembra y la cosecha, ya

${ }^{1}$ Este trabajo se enmarca en el proyecto de autos sacramentales financiado por la Subdirección General de Proyectos de Investigación (FFI2008-02319/FILO) cofinanciado por el FEDER. Cuenta también con el patrocinio de TC-12, en el marco del Programa Consolider-Ingenio (CSD2009-00033), del Plan Nacional de Investigación Científica, Desarrollo e Innovación Tecnológica.

${ }^{2}$ Una sistematización de las estructuras alegóricas en los autos calderonianos puede verse en Arellano, 2001. 
sea del trigo o de la vid como antecedentes del pan y del vino eucarísticos. Como es de esperar, el mecanismo de estos autos encuentra sus mejores pilares en las alegorías bíblicas centradas en la actividad agrícola, especialmente en las parábolas evangélicas ${ }^{3}$ del sembrador (Mateo, 13, 1-23), la semilla y la cizaña (Mateo, 13, 24-30), los obreros de la viña (Mateo, 20,1-16) y los viñadores infieles (Mateo, 21, 33-46; Marcos, 12, 1-12; Lucas, 20, 9-19), que actúan como macrotextos argumentales y se combinan entre sí al interior de cada uno de estos autos en ingeniosas y complejas maneras, que no excluyen el manejo y la integración de otras fuentes y elementos compositivos.

Como es fácil de suponer, los motivos relacionados con las tareas agrícolas (y en especial las que tienen que ver con la cosecha del trigo y la vendimia de la uva) aparecen de forma reiterada en muchísimos autos, pero ahora no me interesa un rastreo sistemático de todas esas menciones. En esta aproximación examinaré exclusivamente cuatro autos en los que tales motivos agrícolas alcanzan un desarrollo nuclear. Me refiero, concretamente, a La semilla y la cizaña (1651), La siembra del Señor (anterior a 1655), La viña del Señor (representado en el corpus de 1674) y El día mayor de los días (auto del corpus de 1678). Centraré mi atención en la relación que se establece en todas estas obras entre el Agricultor divino - representado en las imágenes del sembrador, el mayoral o el padre de familias- y otras figuras o entidades que asumen el papel de agricultores al servicio del primero (los «obreros del Señor», o «jornaleros de la vida», como son denominados en varios pasajes). Dado lo acotado del objetivo del trabajo, dejaré fuera del análisis la presencia de personajes labradores o asociados a la labor campesina en otros autos calderonianos cuyas ocurrencias se inscriben en otros esquemas alegóricos como, por ejemplo, el Labrador de El gran teatro del mundo o los personajes que asumen el rol de trabajadores de la tierra en Las espigas de Ruth.

Veamos en primer término los personajes que dirigen la actividad del campo de la vida como trasunto de Dios. En La siembra del Señor y La viña del Señor la imagen del Agricultor divino se halla figurada en el personaje del Padre de familias. En el primero de esos autos, es quien convoca a los jornaleros para que trabajen en su heredad, los

${ }^{3}$ Para el empleo de las parábolas bíblicas como macrotextos argumentales por parte de Calderón, ver Arellano, 1999, p. 45 y 2001, pp. 89-95. 
cuales acudirán a distintas horas del día — Adán al amanecer; Judaísmo, Apostasía e Idolatría al mediodía; y Fe al atardecer-, siguiendo el lineamiento de la parábola nuclear a partir de la cual se construye el auto, la de los obreros de la viña que son retribuidos por igual a pesar de haberse incorporado a la tarea en distintos momentos (Mateo, $20,1-16)^{4}$. En el segundo caso, la fuente del esquema alegórico es la parábola de los viñadores homicidas (Mateo, 21, 33-46). Aquí el Padre de familias se enfrenta a la traición de unos viñadores infieles (representados por Hebraísmo y Sinagoga) que arriendan su viña y que, llegado el momento de la vendimia, para no pagar los diezmos y las primicias acordadas, matan a sus emisarios (Isaías, Jeremías y Juan Bautista) y a su propio heredero (Cristo).

Esta identificación del «Padre de familias» con Dios que aparece en los autos referidos se encuentra en Mateo, 20, 1-16 y es comentada por Juan de Pineda en sus Diálogos familiares de la agricultura cristiana cuando, para explicar el pasaje evangélico mencionado, dice:

como el cuidado de la gobernación de la familia sea muy grande en el hombre cuerdo, encareció el evangelista el cuidado que Dios tiene de nuestra provisión espiritual, comparándole con el que se muestra haber tenido aquel padre de familia, que es el hombre que tiene casa con gente que sustentar y mantener ${ }^{5}$.

En La siembra del Señor este Padre de familias - que aparece caracterizado en la acotación inicial como «viejo venerable, vestido de mayoral»— convoca él mismo a los trabajadores. El auto se abre con este llamamiento a los obreros para que acudan a la tarea. En ese primer pasaje, además, se presenta a sí mismo y describe la virgen tierra de su heredad (figura de la Virgen María, en el complejo de correspondencias alegóricas):

PADRE

Mortales hijos de Adán que en las fértiles campañas

del universo vivís

a merced de la labranza:

${ }^{4}$ Los elementos bíblicos y alegóricos en este auto han sido estudiados por Mata, 2010, y algunas referencias también en Mata, 2008.

5 Pineda, Diálogos, XVI, 3 (vol. III, p. 123). 


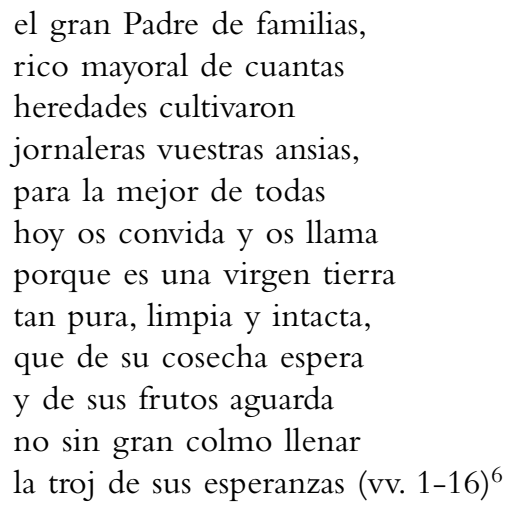

Esta convocatoria en forma de apóstrofe a los «Mortales hijos de Adán» equivale a la llamada universal de Dios, cuyo plan salvífico incluye a toda la humanidad.

En La viña del Señor el Padre de familias aparece caracterizado de la misma manera - como viejo venerable y mayoral- y está acompañado además por su Hijo, vestido de zagal. En este caso, solicita a Lucero del día (Juan Bautista) que llame a los obreros, no como jornaleros, sino como arrendadores de su viña. Cabe señalar que esta aparición del Padre de familias está precedida por un avance enunciativo del desarrollo argumental en réplicas alternas de Lucero del día y de la Música. De este primer pasaje se puede destacar la constante conexión entre el señor de la viña y el señor de la mies, a través de estos dos versos que se repiten varias veces:

LuCero Que el sueldo que os dio el señor de la mies, igual os dará de la viña el señor (vv. 7-8)

Unos versos más adelante este parangón queda aún más explícito en la glosa que Malicia hace de la parábola del sembrador (vv. 118163), después de haber indicado que el sembrador ha comprado el trigo para su siembra al mercader. Con ello la figuración del Agricultor divino se hace todavía más compleja: el señor de la viña ha de actuar como el señor de la mies, que a su vez se relaciona en este mismo ámbito de divinidad con el mercader que lleva el trigo en su nave, en

${ }^{6}$ Cito por la edición de M. Insúa y C. Mata, en prensa. 
clara alusión al auto La nave del mercader que, como indican sus editores -Arellano, Cilveti, Oteiza y Pinillos-, se representó también en el corpus de ese mismo año de 1674. Es más, los versos finales de La nave del mercader anuncian que habrá una segunda parte que versará sobre el vino sagrado (es decir, La viña del Señor).

A continuación Malicia, temerosa de que estas tareas de la mies pasen a la viña, recuerda que el Padre de familias es también labrador, pues su mismo hijo así lo señaló al decir: «mi padre agrícola es» (v. 171), que remite al conocido pasaje de Juan, 15, 1-5, «Pater meus agricola est», comentado entre otros por San Agustín: «Dice el Señor en el Evangelio: Yo soy la vid y vosotros los sarmientos y mi padre el agricultor. ¿Qué hace el agricultor? [...] Pienso que cultiva su campo. Por tanto, si Dios Padre es agricultor, tiene un campo que cultivar del que espera fruto" (sermón 87,2). Con esta alusión al Pater meus agricola est, el atributo de excelso Agricultor del Padre queda plenamente manifestado, esta vez en boca de un personaje perteneciente al bando de los agentes malignos.

En el auto La semilla y la cizaña la figura que representa la agricultura en el nivel divino es el Sembrador, que resulta a su vez semilla. Así se refiere Cizaña a esta extraña coincidencia que la altera y estremece:

CizAÑa Sembrador y semilla,

porque no se qué misterio

en sí guarda, incluye y cifra

ser semilla y sembrador... (vv. 144-147)

Luego relatará la parábola del Sembrador — que, junto con la parábola de la semilla y la cizaña, es la fuente principal del esquema alegórico de este auto- para que se entienda el porqué de la lid a la que está convocando a Cierzo, Niebla e Ira-Langosta. Como señala la parábola evangélica, la semilla puede caer en cuatro lugares diferentes, identificados en el auto con las cuatro partes del mundo, Asia, África, Europa y América, en las cuales habrán de combatir el misterio (v. 393) y el enigma (v. 394) del sembrador que es también semilla.

El final de la arenga de Cizaña coincide con el arribo del Sembrador (caracterizado de galán labrador), que llega en una nave acompañado de Lucero (Juan Bautista) e Inocencia (v. 407 acot.). Con ello se abre una nueva red de paridades, pues el Sembrador es asimismo 
capitán de la nave del mercader (nuevo ejemplo de la utilización del motivo ya mencionado). En este caso, el vínculo alegórico de este sembrador-navegante se justifica además por el hecho de que la parábola del sembrador fue enunciada por Cristo desde una barca. Así se lo hace notar la propia Cizaña a Niebla cuando esta anuncia que el Sembrador está hablando desde el mar:

CizAÑA

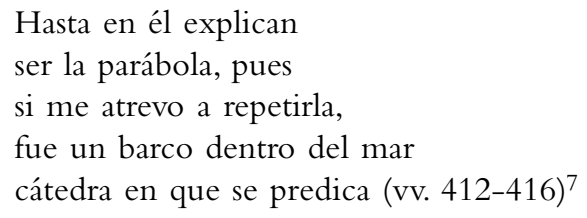

Desde este espacio dramático marino, el Sembrador convocará a la labranza a los mayorales de las cuatro partes del mundo; al mismo tiempo les promete que el trigo que trae en las «entrañas» de su nave dará ciento por uno - como la tierra buena de la parábola del sembrador- y les dice que solo espera a cambio que se le paguen diezmos y primicias en el momento de la cosecha - como sucede en la parábola de los viñadores infieles- (vv. 613-620). Llegada, en efecto, la hora de la cosecha, el Sembrador regresa a la mies, no a cobrar las primicias, sino a unirse a la tarea como un jornalero más. La acotación indica que va vestido de villano ${ }^{8}$, con lo cual se marca visualmente la sencillez de Cristo-Hombre, del Dios encarnado que se muestra ahora como un labrador terreno con traje de «tosca humanidad» (v. 1552); es decir, se expresa así la unión hipostática de Cristo que, siendo Dios, ha asumido plenamente la naturaleza humana. En el parlamento que dirige a los otros agricultores, que supuestamente han cuidado del preciado trigo, hace una alabanza del trabajo duro del campo y se ofrece como el primero en sacrificarse por la labor:

SEMBrador Labradores de la vida, que tenéis en los afanes por tarea los alientos y por jornal los instantes.

7 Cito por la edición de Rodríguez, en preparación.

${ }^{8}$ La explotación simbólica del vestido de villano en los autos es abordada por Arellano, 2001, pp. 212-213. 
Nobles padres de familias, generosos mayorales, que del ámbito del mundo cultiváis las cuatro partes; no tan presto a cobrar vengo tributarios vasallajes, que me han de tocar por frutos de la herencia de mi padre: y así, no os asuste el verme como acreedor, porque antes vengo a ser entre vosotros jornalero, que constante sea el primero que madrugue, sea el primero que trabaje, sujeto a las inclemencias del sol, del agua y del aire, porque a ninguno dificil sea, sino a todos fácil la ley, pues la ayuda mía hará su yugo süave... (vv. 1526-1549)

De la misma manera, también como un obrero más de la labranza de la heredad se presenta Emanuel en el auto de La siembra del Señor, con unas palabras que explicitan su plena asunción de la naturaleza humana y anuncian además la correspondencia del labrador y el trigo:

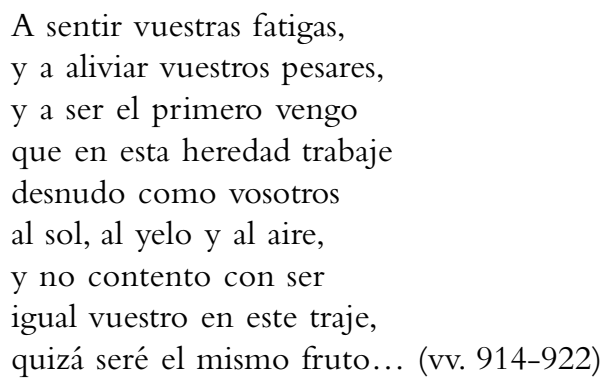

Igualmente, en La viña del Señor el Hijo dice a su Padre que irá a pedir cuentas a los arrendadores de la viña como obrero; de esta forma le tendrán mayor respeto, pues acudirá 
vestido el tosco buriel

de la misma jerga que a él

para su abrigo le dio

la naturaleza humana (vv. 1910-1913)

Asimismo se muestra aquí como un obrero ejemplar que ofrece trabajar más que nadie con tal de conseguir el mejor fruto:

Verás que horror no me dan

ni de la escoda el afán,

ni de la azada el rigor,

pues para que llegue a dar

el grano cosecha inmensa,

el hombro pondré a la prensa

de la viga del lagar.

Envíame a ser tu obrero

en la viña de Israel (vv. 1926-1934)

Nótese que más adelante, de acuerdo con el rico mecanismo alegórico de este auto, el instrumento con el que Hebraísmo da muerte al Hijo, el tronco (la cruz) pertenece al mismo árbol del que se cortó la mencionada viga del lagar (vv. 2128-2131a), lagar en el que el heredero del Padre propone esforzarse afanosamente ${ }^{9}$.

En El día mayor de los días, reescritura del auto La siembra del Señor ${ }^{10}$, Cristo representado como Zagal también se ofrece al Tiempo - caracterización que asume aquí el mayoral, en tanto señor que todo lo gobierna - como buen labrador, indicando además que ese atributo de divino Agricultor le toca igualmente al Padre en la Providencia (vv. 1719-1720). Así se manifiesta a los obreros representantes de la Ley Natural, la Escrita y la de Gracia:

sin pompas ni majestades, me envía a que yo la muestra

le lleve del fruto que hace,

${ }^{9}$ Para un completo análisis de la representación del árbol de la cruz ver Arellano, 2008 y la introducción a su edición de El árbol de mejor fruto.

10 Sobre el fenómeno de reescritura de este auto ver el estudio preliminar de Arellano y Zugasti a la edición del auto, pp. 10-18. 


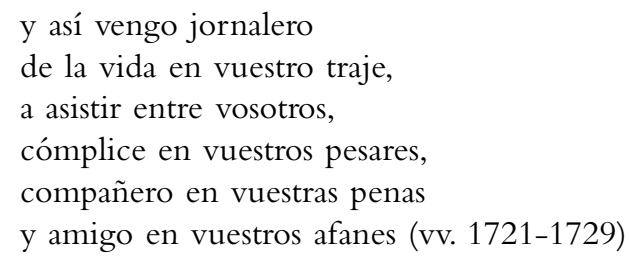

De igual modo que en el auto antecedente, La siembra del Señor, causa extrañeza y desconfianza a los obreros el sencillo atuendo de Zagal (su humanidad) y su llegada sin pompa de rayos ni truenos; situación que, de hecho, sirve de excusa para que Hebraísmo lo muela y quebrante, "porque como trigo mueras, / ya que como trigo naces» (vv. 1792-1793). En La siembra del Señor era la Culpa quien le reprochaba a Emanuel el llegar a la labranza en un traje tan villano, que no permite a los obreros reconocerlo (vv. 974-977), palabras que son eco de Juan, 1, 10.

Paso ahora a revisar los distintos modos de caracterización de los «jornaleros de la vida» en estos cuatro autos de tema agrícola, es decir, de aquellos personajes que asumen la tarea de servir de una manera u otra, ya sea en la siembra, ya en la viña. Esta denominación de «jornaleros de la vida» es recurrente en estas piezas junto con otras como las de «obreros del Señor» o «labradores del Padre». Ese bello marbete de «jornaleros de la vida» tiene su origen en las mismas parábolas que sirven de base argumental a tales obras. En concreto, en Mateo, 20, 1 - parábola de los obreros de la viña - se identifica este espacio con el reino de los cielos y a los hombres como los jornaleros que trabajan en la vida terrena para ganar el salario de la vida eterna. Así interpreta, por ejemplo, Pineda este pasaje evangélico en sus Diálogos familiares de la agricultura cristiana:

el reino de los cielos es semejante al padre de las campañas, que coge trabajadores para su viña; que vale tanto como decir que como pasa en el cuento de esta parábola [Mateo 20], en que el padre de familias es introducido salir muchas veces a coger a quien cave su viña y gane jornal con que se mantener, ansí pasa en el reino desta Iglesia, en la cual sale Dios diversas veces por diversas maneras de llamamientos, con que induce a 
muchos querer aplicarse al trabajo de la virtud por el día desta vida, después de la cual les dará Dios en galardón el dinero de la vida eterna ${ }^{11}$.

Calderón escenifica en estos autos las distintas formas en que los hombres pueden servir al Padre Agrícola: desde la fidelidad absoluta del buen labrador a la infidelidad de los obreros fingidos y nefastos que infectan las tierras productivas y matan la simiente.

En La semilla y la cizaña cada parte del mundo en la que ha de caer la semilla del trigo tendrá su correspondiente mayoral: Asia, el Judaísmo; África, el Paganismo; Europa, la Gentilidad; y América, la Idolatría. Cada uno de los cuatro se verá influenciado por uno de los cuatro enemigos del Sembrador - Cierzo, Ira-Langosta, Niebla y Cizaña, respectivamente-, que se disfrazarán de labradores para acabar con el trigo. De este modo lo explica Cizaña a sus secuaces, al llamarlos a la lid:

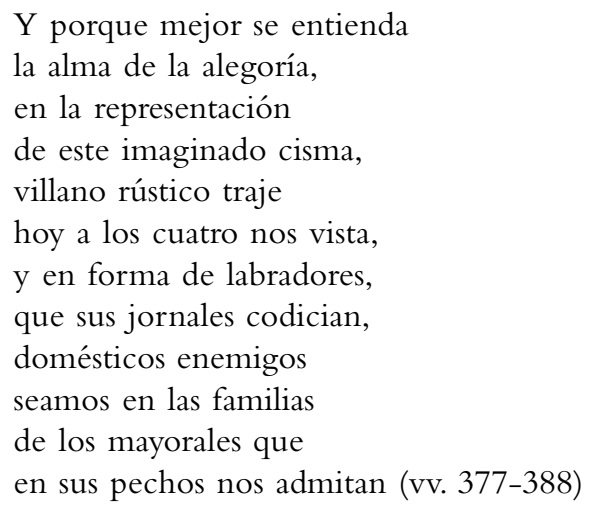

Cada mayoral tiene diferentes reacciones frente a la propuesta del Sembrador. Judaísmo duda de que la simiente pueda echar raíces y se fia del labrador extranjero Cierzo para que cuide la siembra. Paganismo no ha prestado atención al discurso del Sembrador (se ha quedado dormido) y deja todo a la flojedad de su ley, de forma que las semillas quedan abandonadas en el camino e Ira se ofrece a vigilar si prende la mies. Gentilidad se muestra confusa frente al enigma de la semilla,

11 Pineda, Diálogos, I, 22 (vol. I, pp. 53 y ss.).Ver también Mateo, 21, 33-46; Marcos, 12, 1-12; y Lucas, 20, 9-19. 
pero igualmente decide atender la labranza para ver lo que gana o lo que pierde; por ello Cizaña, temerosa de que Europa sea por fin la «sazonada tierra, / que ha de dar por uno ciento» (vv. 1143-1144), envía a la oscura Niebla (la Herejía) para que anuble con la neguilla los verdores del trigo granado. En fin, Idolatría, confiada en la riqueza que las minas de oro y plata de América le tributan, dice que no necesita trabajar en el campo y, prendada de la belleza de Cizaña, se va con ella.

Las acotaciones ponen de manifiesto el fracaso de la cosecha en las cuatro partes del mundo por la acción de estos falsos ayudantes: Asia pierde la corona de espigas verdes; África solo puede mostrar cañas sin espigas; el trigo de Europa es cubierto por un velo; y, en fin, las fértiles tierras de América en lugar de trigo han dado clavellinas y amapolas (representadas en una corona de espinas y hojas). En consecuencia, los mayorales no pueden cumplir con el pago del tributo acordado con el Sembrador, y solamente pueden ofrecerle piedras, una caña, una corona de espinas y un cendal que cubre sus ojos (objetos asociados todos ellos a la crucifixión de Cristo). En efecto, el Sembrador es crucificado por Judaísmo en una cruz construida con el bastón de Gentilidad. Finalmente, tras la consumación del misterio del trigo, el fruto de la palabra sembrada es conducido por el divino Sembrador en su nave, escoltado por Gentilidad y Europa, que son nombradas su heredera y atlante de la fe respectivamente (vv. 1781-1782).

En La siembra del Señor y en El día mayor de los días se advierte una clara estructura tripartita, según la cual la acción de los tres grupos de labradores en la heredad se fundamenta primordialmente en el aspecto temporal: unos llegan al amanecer (Adán en La siembra del Señor y Ley Natural y Adán en El día mayor de los días), otros al mediodía (Judaísmo, Apostasía e Idolatría en el primer auto y Ley Escrita, Moisés y Hebraísmo en el segundo) y, por último, otros se incorporan al atardecer (Fe y Ley de Gracia, respectivamente). Un detalle interesante es que, en el macrotexto argumental, la parábola de los obreros de la viña (Mateo, 20,1-16), el propietario que sale a buscar jornaleros lo hace en cinco ocasiones: a primera hora de la mañana, a la hora tercia, a la sexta, a la nona y a la undécima. En cambio, en los dos autos el esquema se reduce a tres momentos temporales y tres grupos de obreros, precisamente para que se correspondan con las tres etapas de la historia de la salvación humana, es decir, la Ley Natural, la Escrita 
y la de Gracia. Esta estructura asentada en el factor temporal se hace más patente en El día mayor de los días a través de la paridad entre el mayoral y el Tiempo; todo el desarrollo apunta además desde el título hacia una meta que también está asociada al cronos: «el día mayor de los días».

En La siembra del Señor Adán y cuatro labradores, representantes de la Ley Natural, se muestran como obreros sufrientes que cultivan la tierra con dolor y esfuerzo, entre cantos (habituales como acompañamiento de las tareas agrícolas) y lágrimas. La misión que les ha encomendado el Padre de familias es la de preparar la tierra "para que conciba y para / Verbo y Trigo" (vv. 522-523), labor que han de hacer exclusivamente con suspiros y llantos - muestra del arrepentimiento necesario para merecer la redención de su culpa. Cabe señalar además que la acción de Adán como labrador se ajusta perfectamente al esquema alegórico porque la tierra-Virgen no puede ser tocada por el hierro de su azada (por el yerro de su pecado original). En El día mayor de los días el padecimiento de Adán labrador, mayoral de la escuadra de la Ley Natural, también es su rasgo definitorio. Así le dice al Tiempo:

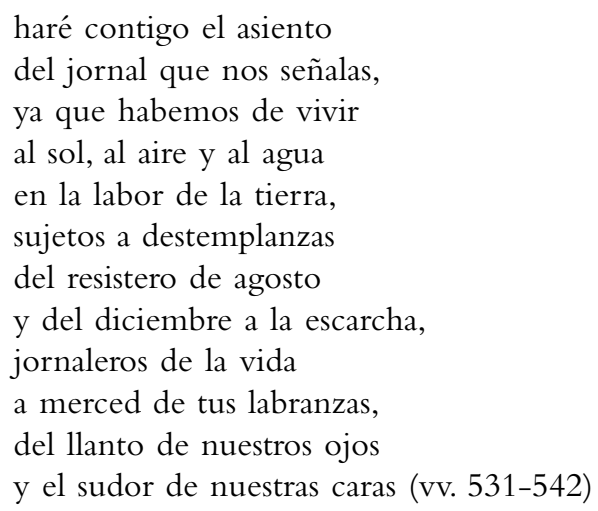

En ambos autos al segundo grupo de obreros se le encarga recoger el fruto; en El día mayor de los días los labradores de la Ley Escrita relevan a los primeros en la tarea mientras estos duermen la siesta. Cabe señalar que en el momento de presentarse ante el mayoral Ley Escrita acentúa el temor por haber llegado tarde, aspecto también pre- 
sente en La siembra del Señor (vv. 653-655), pero no con tanto énfasis como ocurre aquí:

LEY ESCRITA

Porque,
temerosa, me embaraza
pensar que he venido tarde
ante quien con todos tasa
los instantes, para que
de instantes las horas se hagan,
y de las horas los días,
de los días las semanas,
de las semanas los meses,
y de ellos los años, hasta
siglos de siglos que cumplan
el día que en tu mente trazas
que sea el mayor de los días
cuando juntes sus distancias (vv. 689b-702)

En La siembra del Señor Culpa, a sugerencia de Sueño, determina que los segundos obreros (Judaísmo, Idolatría y Apostasía) sean los enemigos del trigo y les encarga las tareas correspondientes: Idolatría segará la mies (su instrumento será una guadaña, que equivale a la hoz del segador); Apostasía aventará el trigo segado (con un palo con tres clavos, a modo de bieldo); y Judaísmo trillará y molerá (el objeto que saca es una cruz, equiparada al trillo). Según declara Sueño, Idolatría actuará como la langosta que tala; Apostasía como la neguilla que confunde (la neguilla, según indica Covarrubias, es una simiente negra que estropeaba la harina del trigo); y Judaísmo como la cizaña que puede malograr por completo la cosecha. En El día mayor de los días Noche (Culpa) también se vale de Idolatría, Hebraísmo y Apostasía, que "son una / en cuanto al odio a esta siembra» (vv. 1354-1355), y los incita a no huir de la heredad sino a ser enemigos desde dentro, como «ladrones de casa» (v. 1376). La paridad de estos tres enemigos con langosta, neguilla y cizaña es idéntica a la del auto anterior.

En La siembra del Señor Fe (Ley de Gracia), representante de los trabajadores que llegan en tercer lugar, arriba a una heredad ya yerma, con el trigo segado y maltratado. Así se presenta ante el mayoral como capitana de una unión de fieles (el gremio militante de la Iglesia) dispuestos a trabajar en la heredad aunque casi sea de noche. El Padre 
de familias responde que, si bien han llegado tarde, les dará el mismo salario que a los anteriores: si la Fe le sirve bien, esto es, si acaba la labor comenzada en la heredad por los otros obreros, no le pagará mal, le indica. Asistimos así al inicio de la Ley de Gracia y avanzamos hacia la exaltación eucarística final del auto. Por su parte, en El día mayor de los días el personaje de la Ley de Gracia entra en escena antes de la muerte de Zagal (Hijo). Ingenio, Pensamiento y Tiempo la encuentran con una tropa de gente descansando ociosamente, «mantenida de sola la esperanza» (v. 860); nuevamente se recalca el aspecto temporal, esta vez de la espera. En este caso, Tiempo encomienda a Ley de Gracia que se ocupe de llevar el trigo al pósito de Belén (recuérdese a este propósito la etimología de Belén como 'casa de pan').

Para terminar, un último alcance a propósito de La viña del Señor, donde los agentes de la traición son los arrendadores de la viña, Hebraísmo y su esposa Sinagoga, impulsados por dos falsos servidores, Malicia (que se disfraza de Inocencia) y Lucero de la noche. Este último se presenta sagaz diciendo que sabe de agricultura y que

No hay árbol, planta o flor que de mi ingenio la oculta cualidad tenga segura:

algún tronco pudiera

decirlo (vv. 1251-1255a)

Este «tronco» hace referencia, por supuesto, al del árbol del Paraíso, donde Adán y Eva fueron tentados.

En correspondencia con el macrotexto argumental — la parábola de los viñadores infieles-, Hebraísmo, impulsado por Sinagoga, mata a los cobradores de las primicias de la vendimia: Isaías, Jeremías, Lucero de la mañana (Juan Bautista) y, por último, el heredero del mayoral. En este auto el elemento agrícola, propio del tiempo de la cosecha de la uva que ha de transformarse en vino sacramentado, se combina con un conjunto más complejo de referencias a otros campos alegóricos, por ejemplo el del convite (Sinagoga prepara un ágape para celebrar que su esposo ha expulsado a los cobradores del mayoral $)^{12}$.

12 Para un análisis completo de los campos alegóricos de La viña del Señor puede consultarse el estudio preliminar de Arellano, Cilveti, Oteiza y Pinillos a la edición de este auto. 
En conclusión, y según hemos podido apreciar, en el universo dramático de estos cuatro autos calderonianos, la heredad y la viña, la siembra y la cosecha, la mies y la vid, que redundarán en «dulces frutos» ${ }^{13}$; los instrumentos de labranza (bieldos, guadañas y trillos); los espacios de producción y recolección (la tierra de sembradío, el lagar, el pósito...); los enemigos del fruto (langosta, cizaña y neguilla), jalonados por cantos de labradores que acompañan la tarea, se combinan ingeniosamente para manifestar en «figura y figurado» la historia de la redención humana.

\section{BiBLIOGRAFÍA}

Agustín, San, Sermones, Madrid, BAC, 1981-1985, 6 vols.

Arellano, I., «Notas sobre la Biblia en los autos de Calderón», en V Simposio Bíblico Español. La Biblia en el arte y en la literatura, vol. I, Literatura, ed.V. Balaguer y V. Collado, Valencia / Pamplona, Fundación Bíblica Española / Universidad de Navarra, 1999, pp. 17-52.

- Diccionario de los autos sacramentales de Calderón, Kassel, Reichenberger, 2000.

- Estructuras dramáticas y alegóricas en los autos de Calderón, Kassel, Reichenberger, 2001.

— «El árbol del mejor fruto de Calderón y la leyenda del árbol de la cruz. Contexto y adaptación", Anuario calderoniano, 1, 2008, pp. 27-65.

Calderón de la Barca, P., El árbol de mejor fruto, ed. I. Arellano, Kassel, Reichenberger, 2009.

- El día mayor de los días, ed. I. Arellano y M. Zugasti, Kassel, Reichenberger, 2004.

- La nave del mercader, ed. I. Arellano con la colaboración de B. Oteiza, M. C. Pinillos, J. M. Escudero y A. Armendáriz, Kassel, Reichenberger, 1996.

- La semilla y la cizaña, ed. D. Rodríguez, en preparación.

- La siembra del Señor, ed. M. Insúa y C. Mata, en prensa.

- La viña del Señor, ed. I. Arellano, Á. Cilveti, B. Oteiza y M. C. Pinillos, Kassel, Reichenberger, 1996.

MatA, C., "Entre Rojas Zorrilla y Calderón: en torno a la autoría de Los obreros del Señor / La siembra del Señon, en Rojas Zorrilla en su IV Centenario. Congreso Internacional (Toledo, 4-6 de octubre de 2007), ed. F. B. Pedraza, R.

13 Denominación que aparece en La viña del Señor, v. 2418. 
González Cañal y E. Marcello, Toledo, Universidad de Castilla-La Mancha, 2008, pp. 697-708.

- «Los elementos bíblicos y la alegoría en el auto sacramental La siembra del Señor de Calderón", en La Biblia en la literatura del Siglo de Oro, ed. I. Arellano y R. Fine, Madrid / Frankfurt, Iberoamericana / Vervuert, 2010, pp. 339-355.

PinedA, J. de, Diálogos familiares de agricultura cristiana, ed. J. Meseguer, Madrid, Atlas, 1963, BAE, vols. 161-163 y 169-170.

Sagrada Biblia, Pamplona, Eunsa, 1983. 